ISSN 0103-5150

Fisioter. Mov., Curitiba, v. 28, n. 1, p. 169-186, Jan./Mar. 2015

Licenciado sob uma Licença Creative Commons

DOI: http://dx.doi.org.10.1590/0103-5150.028.001.AR02

(c) (

\title{
Assessment of the strength of the trunk and upper limb muscles in stroke subjects with portable dynamometry: a literature review
}

\author{
Avaliação da força muscular pós-AVE pela dinamometria \\ portátil: uma revisão da literatura
}

Júlia Caetano Martins, Luci Fuscaldi Teixeira-Salmela, Larissa Tavares Aguiar, Lucas Araújo Castro e Souza, Eliza Maria Lara, Christina Danielli Coelho de Morais Faria*

Universidade Federal de Minas Gerais (UFMG), Belo Horizonte, MG, Brazil

\section{Abstract}

Introduction: Clinical measurements of strength in stroke subjects are usually performed and portable dynamometers are one of the most employed instruments. Objective: To verify the standardization procedures of the methods used to assess the strength of the trunk and upper limb muscles with portable dynamometers in stroke subjects, as well as to assess the psychometric properties which were already investigated. Materials and methods: An extensive search was performed on the MEDLINE, SCiELO, LILACS, and PEDro databases, by combining specific key words, followed by active manual searches by two independent researchers. Results and discussion: Fifty-eight studies were included: three related to the trunk and 55 to the upper limb muscles, including handgrip and pinch strength assessments. The most investigated muscular groups were handgrip, elbow flexors/extensors, wrist extensors, and lateral pinch. Nine studies reported adequate reliability

\footnotetext{
*JCM: MSc, e-mail: julia_caetano@yahoo.com.br LFTS: Ph.D, e-mail: lfts@ufmg.br LTA: Grad., e-mail: larissatavaresaguiar@gmail.com LACS: MSc, e-mail: lucas.araujo.ufmg@gmail.com EML: Grad., e-mail: izamlara@yahoo.com.br CDCMF: PhD, e-mail: cdcmf@ufmg.br
} 
levels and the seated position was employed in the majority of the studies which assessed trunk, handgrip, and pinch strength, while the supine position was used for the other muscular groups. The number of trials most used was three, while the reported contractions and rest times were variable. Final considerations: Most studies reported the positioning and/or the data collection protocols; however, there was no consensus on the standardization procedures. The only investigated psychometric property was reliability. Few studies evaluated the trunk muscles and other psychometric properties.

Keywords: Dynamometer. Trunk. Upper limbs. Reliability. Validity.

\section{Resumo}

Introdução: A mensuração da força muscular em indivíduos acometidos pelo Acidente Vascular Encefálico (AVE) é comumente realizada na clínica, sendo os dinamômetros portáteis os instrumentos mais utilizados para tanto. Objetivo: Verificar se há uma padronização dos métodos utilizados para avaliação da força muscular de tronco e membros superiores (MMSS) com o uso de dinamômetros portáteis em indivíduos pós-AVE, bem como verificar quais propriedades de medida já foram investigadas. Materiais e métodos: As buscas foram realizadas nas bases de dados MEDLINE, SciELO, LILACS e PEDro com combinação de termos específicos, seguidas de busca manual ativa. A seleção dos estudos e a extração das informações foram realizadas por dois examinadores independentes. Resultados e discussão: Foram incluídos 58 estudos (três de tronco e 55 de MMSS, incluindo preensão manual e pinça). Os grupos musculares mais avaliados foram preensão manual, flexores de cotovelo, extensores de punho, extensores de cotovelo e pinça lateral. Nove estudos reportaram confiabilidade adequada do método. A maioria dos estudos que avaliaram os músculos de tronco, de preensão manual e de pinça utilizou a postura sentada, enquanto o decúbito dorsal foi mais utilizado na avaliação dos demais músculos. $O$ número de repetições mais utilizado foi três, já o tempo de contração e o período de repouso variaram entre os estudos. Considerações finais: A maioria dos estudos relatou o posicionamento e/ou o protocolo de coleta, porém não houve uma padronização. A única propriedade de medida investigada foi a confiabilidade. Poucos estudos avaliaram os músculos de tronco e as outras propriedades de medida.

Palavras-chave: Dinamômetro. Tronco. Membros superiors. Confiabilidade. Validade.

\section{Introduction}

Stroke is an important cause of disabilities. Every year, thousands of working-age adults become partially or totally disabled by this health condition (1), which results in emotional distresses for the patients and their families and socio-economic impact on the health systems (2). Stroke subjects may demonstrate several impairments, being the motor ones the most common (3-5) and those that affect the performance of daily life activities (6).

Among the observed motor impairments, muscular weakness has shown significant associations with activity limitations $(3,7,8)$ and social participation restriction $(7,8)$. Specifically, weakness of the upper limb (UL) (9-13) and trunk $(14,15)$ muscles, which are involved in the performance of many basic, instrumental, work, and leisure activities, lead to important functional limitations. About $70 \%$ of the subjects with paresis of the UL muscles have some degree of functional limitation $(13,16,17)$. Moreover, after the onset of the hemiparesis, stroke subjects demonstrate difficulties in moving and controlling their trunk (18), which affect their balance, transfer, gait performance, and independence in many daily activities (15). Thus, the strength of the UL and trunk muscles strength become an important outcome to be evaluated and considered within the clinical decision-making process for the rehabilitation of stroke subjects.

Within clinical settings, the assessment of the strength of the UL and trunk muscles in subjects with stroke is commonly performed with the manual muscle test (MMT). However, due to its subjectivity and the difficulty to evaluate and differ between the degrees of strength rated as good and normal (grades four and five) $(19,20)$, it is necessary to use more 
objective and sensitive measures to detect changes in strength, such as the portable and isokinetic dynamometers (19). Portable devices, such as the handheld, handgrip, and pinch dynamometers, are more easily applied within clinical settings, when compared to the isokinetic dynamometer (21).

The portable dynamometers, which record the maximal isometric force generated during an isometric contraction (22), have been used to assess the strength of the trunk $(14,23)$, UL $(24-27)$, and handgrip $(9,12,28)$ and pinch $(29-31)$ muscles of subjects with stroke. They are practical devices that can be placed between the examiner's hand and the muscle group to be tested, similar to the MMT assessment (32) or used with the subject exerting force directly on the equipment, in the case of handgrip and pinch assessments (33-36). Furthermore, they provide quantitative measures of strength, which has an important advantage, compared to the MMT assessment (37).

Studies have reported several factors that could influence the measures obtained with portable dynamometers $(21,33)$, such as positioning of the subjects and the device, number of repetitions, contraction and rest time, prior demonstration and familiarization with the procedures, and supply of verbal or visual encouragement. Other factors should also be considered when selecting these devices for the assessment of strength in subjects with stroke, such as unilateral or bilateral assessments and the measurement properties already established for this specific population. Before the portable dynamometers be appropriately employed for the measurement of the strength of the UL and trunk muscles of subjects with stroke, it is necessary to standardize the assessment procedures and to ensure that they show appropriate psychometric properties. Within this context, the aims of this study were to investigate whether there were standardized protocols for the use of the portable dynamometers for the assessment of the strength of the UL and trunk muscles, including handgrip and pinch strength, in subjects with stroke, and verify the investigated psychometric properties. Based upon the results of this review, it will be possible to determine the most commonly used protocols and the psychometric properties, to allow a scientifically-based clinical decision making regarding the use of portable dynamometry for the assessment of the UL and trunk muscles in subjects with stroke.

\section{Methods}

Initially, electronic searches were performed in MEDLINE (via PUBMED), SciELO, LILACS, and PEDro databases. The MEDLINE search strategy followed guidelines developed by the Cochrane group (38), which was adjusted for the other databases, using descriptors related to UL, trunk, and handheld dynamometry. The search terms used for the UL included words related to handgrip and pinch, were: upper limb, upper extremity, hand grip, palmar grip, grip, grasp, hand strength, pinch, hand, and palmar. For the trunk, the search terms included word related to back, trunk, abdomen, and thorax. Finally, for the dynamometry, the following words were used: Dynamometer, pinch gauge, pinch strength, Preston pinch gauge, Jamar, handheld dynamometer, and muscle strength.

To be included, the studies should clearly report in the methodology section that the strength of the trunk or UL muscles, including handgrip or pinch strength, with portable dynamometers was assessed in subjects with stroke. There were no restrictions regarding the language of publication and all studies published until November 2011 were included.

The selection of the studies was performed by two independent examiners, following three steps, as recommended and commonly used (39-41). The first step consisted of reading the titles and excluding the that clearly did not meet the established criteria (39-41). Then, the selected abstracts were analyzed and those that did not meet the inclusion criteria were also excluded (39-41). The last step consisted of reading the full papers. An active manual search from all selected studies was also performed, following the same previously described criteria and procedures.

\section{Results}

The electronic search identified 202 studies. After screening the titles, 122 were excluded for the following reasons: the population was not stroke individuals or the dynamometer was not portable. In the second step, 33 studies were excluded for the same reasons or for not assessing the strength of the trunk or UL muscles. In the third step, eight studies were excluded. Of the 39 studies that met the inclusion criteria, five could not be retrieved. Thus, 34 studies retrieved by the electronic search were included in this review. From the active manual search in these 
34 studies, 24 others were included. Therefore, a total of 58 studies fulfilled all eligibility criteria and were included in this review (Figure 1).

Amongst the 58 included studies, three evaluated the strength of the trunk $(5.17 \%)(14,23,42)$, while $55(94.83 \%)$ analyzed the strength of the UL muscles, including handgrip and pinch strength. Out of the 55,41 assessed handgrip $(4,9,12,28,31,43-78)$, 15 pinch $(29-31,47,54,55,57,58,61,71,76,78-$ 81 ), and 17 the strength of other UL muscles (24-27, $46-48,55,59,63,70,76,82-86)$. The studies that measured the strength of the trunk muscles included 59 individuals of both sexes, who had ages ranging from 27 to 87 years and were at the acute stages (three to 27 days post-stroke). Those that assessed handgrip strength included 1,408 individuals of both sexes, who had ages ranging from 16 to 93 years and the time since the onset of stroke ranging from two days to 30 years. The studies which assessed pinch strength included 536 subjects of both sexes, who had ages ranging from 16 to 94 years and the time since the onset of the stroke ranging from two days to 23 years. The studies which evaluated other UL muscles included 468 individuals of both sexes, who had ages ranging from 17 to 89 years and the mean time since the onset of stroke ranging from two days to 30 years.

Regarding the trunk muscles (Table 1), the anterior flexors were evaluated in two studies (66.7\%) $(14,42)$ and the lateral flexors in all three included studies $(100 \%)(14,23,42)$. In all studies, the seated position was used and two reported the data collection protocols, describing the number of trials and the duration of the isometric contractions $(14,42)$. One study (33.3\%) performed unilateral assessment of the lateral flexors (23) and two (66.7\%) bilateral $(14,42)$.

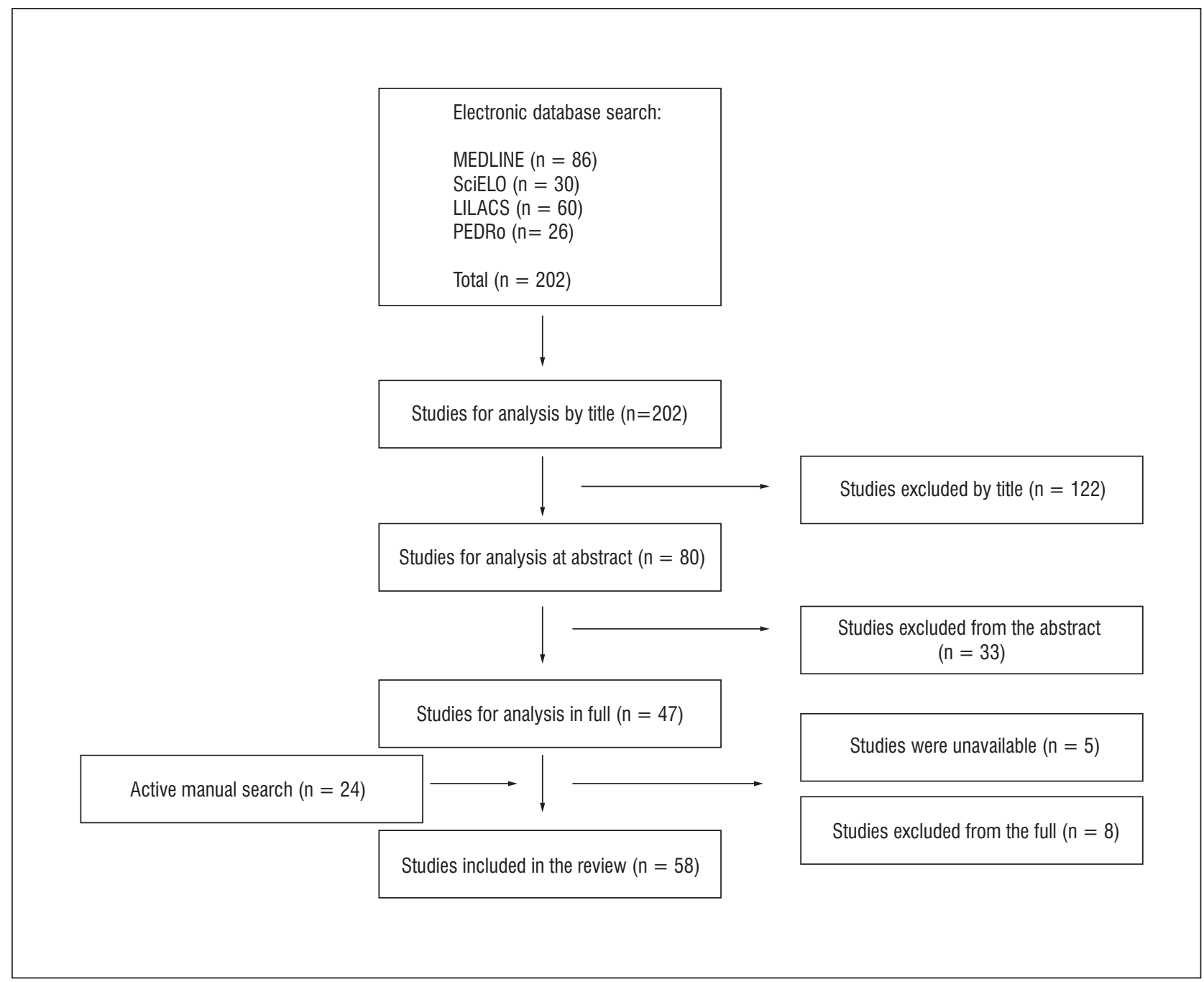

Figure 1 - Flow chart of the selection of the studies 
Table 1 - Data extraction of the studies which assessed the strength of the trunk muscles in subjects with stroke with portable dynamometers

\begin{tabular}{llll}
\hline Study & Muscular group & Subject positioning & Protocol \\
\hline Bohannon (23) & Lateral flexors & Sitting and trunk stabilization & $\mathrm{NI}$ \\
Bohannon (14) & Anterior and lateral flexors & $\begin{array}{l}\text { Sitting, stabilization by the } \\
\text { examiner in the proximal thigh }\end{array}$ & $\begin{array}{l}\text { One trial, maximal isometric } \\
\text { contractions over 5s }\end{array}$ \\
Bohannon et al. (42) & Anterior and lateral flexors & $\begin{array}{l}\text { Sitting, stabilization by the } \\
\text { examiner in the proximal thigh }\end{array}$ & $\begin{array}{l}\text { One trial, maximal isometric } \\
\text { contractions over 3 to 4s }\end{array}$ \\
\hline
\end{tabular}

Note: $\mathrm{Nl}=$ not informed.

From the 41 studies that evaluated handgrip strength, 24 (58.54\%) provided detailed information regarding the subjects' positioning or the data collection protocols (Table 2). Since 17 studies did not provide this information (43-59), they were not included in the table. As can be seen in Table 2, the seated position was employed in 11 studies (73.33\%) $(9,12,28,31,62,63,65,70,72,76,77)$. Twenty-two studies reported the number of trials and the majority of them performed three trials $(72.73 \%)(9,12$, $28,31,60,61,64,65,67,68,71-73,75,76,78)$. The duration of the maximal isometric contractions was reported by five studies, and 10 seconds was the time most commonly used $(60 \%)(28,65,69)$. The resting time was reported in seven studies with alternated measurements between the UL being the most employed method $(42.9 \%)(12,68,74)$. Eighteen studies $(69.2 \%)$ repoted bilateral measures of handgrip strength $(4,9,12,28,47,48,52,54-56,59,61,62$, $68,72,74,76,77)$, while eight (30.8\%) only assessed the paretic limb $(31,45,58,64,65,70,71,73)$.

From the 15 studies that assessed pinch strength, lateral pinch was evaluated by nine $(29-31,47,57$, $58,61,78,81)$, the palmar pinch by seven $(47,54,55$, $57,61,76,78)$, pulp-to-pulp pinch by two $(78,80)$ and tip-to-tip pinch by one (81). Two studies did not specify the type of pinch that was measured $(71,79)$. As observed in Table 3, five studies did not provide information regarding the subjects' positioning or data collection protocols $(47,54,55,57,58)$. The seated position was adopted by all four studies that provided information regarding the participants' positioning $(29-31,76)$. Ten studies reported the number of trials, and seven used three trials $(70 \%)(31,61,71$, $76,78,80,81)$. The duration of the contractions was reported by only one study (30), and varied from 1 to 3 seconds. Three studies reported different resting times between the trials: 10s (79), 15s (81), and 30s (80). Six studies (50\%) assessed bilateral pinch strength $(47,54,55,61,76,80)$ and six $(50 \%)$ only the paretic side $(29-31,58,71,81)$.

The main evaluated other muscular groups of the UL (except for handgrip and pinch strength) were the wrist flexors: eight studies $(24,46,48,55,59,76,82$, 83); wrist extensors: 13 studies (24-27, 46-48, 55, $59,76,82,83,86)$; elbow flexors: 17 studies (24-27, $46-48,55,59,63,70,76,82-86)$; elbow extensors: ten studies $(24,25,27,46,48,55,59,76,82,83)$; shoulder flexors: nine studies $(24,25,46-48,55,59,76$, 82); shoulder extensors: eight studies $(24,25,46,48$, $55,59,76,82)$; internal shoulder rotators: five studies $(24,25,59,82,83)$; external shoulder rotators: six studies $(24-26,59,82,83)$; and shoulder abductors: nine studies $(24,25,27,46,48,63,70,82,86)$. Other muscular groups, such as the shoulder adductors $(24$, $82)$ and flexors $(55,76)$ and extensors of the index finger $(55,76)$ were evaluated in two studies.

Of the 17 studies, three did not describe the subjects' positioning or the data collection protocols (46, $48,59)$. Fifteen reported the subjects' positioning and $14(93.3 \%)$ used the supine $(24-27,47,55,63,70,76$, $82-86)$ and one (6.7\%) the seated position (47). Nine studies reported the number of trials and three trials $(44.44 \%)$ were employed in the majority of the studies $(24,25,82,83)$. Nine studies described the duration of the maximal isometric contractions and seven (77.8\%) used 4 to 5 seconds $(24-26,70,82,84,85)$. For the rest time, five studies $(71.43 \%)$ reported 10 to 30 seconds $(24,25,82-84)$, and two $(28.58 \%) 1$ to 2 minutes between the trials $(27,70)$. Table 4 shows the data of the studies that examined the strength of other UL muscles, but the three studies that did not 
describe the subjects' positioning or data collection protocol were not included. Most studies, $11(73.3 \%)$, performed bilateral measures $(25,27,46-48,55,59$, $76,82,83,86)$ and four $(26.7 \%)$ unilateral $(26,70$, $84,85)$, three of the paretic hand.

Regarding the positioning of the dynamometers, two studies on trunk assessment reported that the device was placed in the lower portion of the jugular notch for the anterior trunk flexors, and in the lateral lower portion of the acromion for the lateral trunk flexors $(14,42)$. For the assessment of handgrip strength, the device was positioned between the palm of the hand and the fingers $(12,65)$ with its handle on the second position $(70,77)$. For the evaluation of pinch strength, the end portion of the device was placed between the thumb and the finger involved in the assessed pinch $(29,30,81)$. Studies of other
UL muscles reported that the device was positioned perpendicular to the evaluated segment in its distal region, and stabilization was provided to the proximal region $(24-27,55,63,70,76,82-85)$.

Out of the 58 included studies, nine reported the psychometric properties of the portable dynamometers. In these studies, the strength of the trunk (42) and some UL muscles (24-26, 63, 83-85), including handgrip $(9,28,63)$, were evaluated, as shown in Table 5. All studies assessed the reliability, five reported test-retest $(9,24,25,28,63)$, one intra-rater (85), two inter-rater $(26,42)$, and one intra- and inter-session reliabilities (83). All studies that investigated the psychometric properties of the dynamometer, except one (28), reported the magnitudes of the correlation coefficient values above 0.80 , indicating excellent reliability (87).

Table 2 - Data extraction of the 24 studies which assessed handgrip strength in subjects with stroke with portable dynamometers and provided information regarding the subject' positioning or the data collection protocol

(To be continued)

\begin{tabular}{|c|c|c|}
\hline Study & Subject position & Protocol \\
\hline Sunderland et al. (12) & Sitting, hand on the thigh & Three alternate trials \\
\hline Jones et al. (60) & Upper limb extended next to the body & Three trials \\
\hline Van Deusen et al. (61) & $\mathrm{NI}$ & Three trials \\
\hline Robinson et al. (62) & Sitting, elbow extended & Two trials, contraction of $6 \mathrm{~s}$ \\
\hline Bohannon (63) & $\begin{array}{l}\text { Sitting, upper limb extended next to the } \\
\text { body, elbow flexed to } 90^{\circ}\end{array}$ & $\mathrm{NI}$ \\
\hline Marque et al. (64) & Upper limb down and away from the body & Three trials, rest interval of $5 \mathrm{~min}$ \\
\hline Boissy et al. (9) & $\begin{array}{l}\text { Sitting, shoulder abducted to } 30^{\circ} \text { and } \\
\text { flexed to } 0^{\circ} \text {, elbow flexed to } 90^{\circ}\end{array}$ & Three trials, rest interval of $2 \mathrm{~min}$ \\
\hline Bhakta et al. (65) & $\begin{array}{l}\text { Sitting, elbow flexed to } 90^{\circ} \text { and elbow } \\
\text { extended }\end{array}$ & Three trials, contraction of $10 \mathrm{~s}$ \\
\hline Merians et al.(66) & $\mathrm{NI}$ & One trial \\
\hline Pandyan et al. (67) & $\begin{array}{l}\text { Elbow flexed to } 90^{\circ} \text {, minimum elevation of } \\
\text { the shoulder }\end{array}$ & Three trials, rest interval of $15 \mathrm{~s}$ \\
\hline Hammer et al. (28) & $\begin{array}{l}\text { Sitting, feet resting, hand and forearm } \\
\text { stabilized, elbow flexed to } 90^{\circ} \text { shoulder } \\
\text { flexed to } 10^{\circ} \text { and abducted to } 10^{\circ}\end{array}$ & $\begin{array}{l}\text { Three trials, contraction of } 10 \text { s, rest } \\
\text { interval } \geq 30 \text { s }\end{array}$ \\
\hline Dijkerman et al. (68) & Elbow flexed to $90^{\circ}$ & Three alternate trials \\
\hline Broeren et al. (69) & $\mathrm{NI}$ & Contraction of 10 s \\
\hline
\end{tabular}


Table 2 - Data extraction of the 24 studies which assessed handgrip strength in subjects with stroke with portable dynamometers and provided information regarding the subject' positioning or the data collection protocol

\begin{tabular}{lll}
\hline Study & Subject position & Protocol \\
\hline Bohannon (70) & $\begin{array}{l}\text { Sitting, shoulder adducted, elbow flexed } \\
\text { to } 90^{\circ} \text {, wrist extended between } 0^{\circ} \text { to } 30^{\circ},\end{array}$ & One trial \\
ulnar deviation between $0^{\circ}$ to $15^{\circ}$ & \\
Suputtitada et al. (71) & $\mathrm{NI}$ & Three trials \\
Kamper et al. (4) & $\mathrm{NI}$ & Two trials \\
Wolf et al. (72) & Sitting, elbow flexed to $90^{\circ}$ & Three trials, contraction of 3s \\
Restemeyer et al. (73) & $\mathrm{NI}$ & Three trials \\
Ploughman et al. (31) & $\begin{array}{l}\text { Sitting, elbow flexed to } 90^{\circ} \text {, without trunk } \\
\text { support }\end{array}$ & Three trials \\
Gosselin et al. (74) & $\mathrm{NI}$ & Two alternate trials \\
Kang et al. (75) & $\mathrm{Nl}$ & Three trials \\
Beebe et al. (76) & Sitting, upper limb next to the body, elbow & Three trials \\
flexed to $90^{\circ}$, wrist slightly extended & Sitting, shoulder adduced, elbow flexed \\
to $90^{\circ}$ & One trial \\
\hline Bohannon (77) & $\mathrm{Nl}$ & Three trials \\
\hline
\end{tabular}

Note: $\mathrm{Nl}=$ not informed. The assessment of strength was performed with isometric contractions in all studies.

Table 3 - Data extraction of the 15 studies which assessed pinch strength in subjects with stroke with portable dynamometers

(To be continued)

\begin{tabular}{llll}
\hline Study & Pinch type & Subjects' position & Protocol \\
\hline Van Deusen et al. (61) & Lateral and palmar & $\mathrm{NI}$ & Three trials \\
Conforto et al. (29) & Lateral & $\begin{array}{l}\text { Sitting, shoulder adducted, elbow flexed } \\
\text { to } 90^{\circ} \text {, wrist extended between } 0^{\circ} \text { to } 30^{\circ}, \\
\text { ulnar deviation between } 0^{\circ} \text { to } 15^{\circ}\end{array}$ & Five trials \\
Byl et al. (47) & Lateral and palmar & $\mathrm{NI}$ & $\mathrm{NI}$ \\
Suputtitada et al. (71) & Pinch strength & $\mathrm{NI}$ & Three trials \\
Hummel et al. (30) & Lateral & $\begin{array}{l}\text { Sitting, shoulder adducted, elbow flexed } \\
\text { to } 90^{\circ} \text {, wrist extended between } 0^{\circ} \text { to } 30^{\circ}, \\
\text { ulnar deviation between } 0^{\circ} \text { to } 15^{\circ}\end{array}$ & $\begin{array}{l}\text { Nine trials, contraction between } \\
1 \text { and } 3 \mathrm{~s}\end{array}$ \\
Lomarev et al. (79) & Pinch strength & $\mathrm{NI}$ & Five trials, rest interval of $10 \mathrm{~s}$ \\
McDonnell et al. (80) & Pulp-to-Pulp & $\mathrm{NI}$ & Three trials, rest interval of $30 \mathrm{~s}$
\end{tabular}


Table 3 - Data extraction of the 15 studies which assessed pinch strength in subjects with stroke with portable dynamometers

(Conclusion)

\begin{tabular}{|c|c|c|c|}
\hline Study & Pinch type & Subjects' position & Protocol \\
\hline Lang et al. (54) & Palmar & $\mathrm{NI}$ & $\mathrm{NI}$ \\
\hline Ploughman et al. (31) & Lateral & $\begin{array}{l}\text { Sitting, elbow flexed to } 90^{\circ} \text {, without trunk } \\
\text { support }\end{array}$ & Three trials \\
\hline Beebe et al. (55) & Palmar & $\mathrm{NI}$ & $\mathrm{NI}$ \\
\hline Klaiput et al. (81) & Lateral and pulp-to-pulp & $\mathrm{NI}$ & Three trials, rest interval of $15 \mathrm{~s}$ \\
\hline Beebe et al. (76) & Palmar & $\begin{array}{l}\text { Sitting, upper limb next to the body, elbow } \\
\text { flexed to } 90^{\circ} \text {, wrist slightly extended }\end{array}$ & Three trials \\
\hline Connelly et al. (57) & Lateral and palmar & $\mathrm{NI}$ & $\mathrm{NI}$ \\
\hline Burdea et al. (78) & $\begin{array}{l}\text { Pulp-to-pulp, lateral and } \\
\text { palmar }\end{array}$ & $\mathrm{NI}$ & Three trials \\
\hline Triandafilou et al. (58) & Lateral & $\mathrm{NI}$ & $\mathrm{NI}$ \\
\hline
\end{tabular}

Note: $\mathrm{NI}=$ not informed. The assessment of muscular strength was performed with isometric contraction for all studies.

Table 4 - Data extraction of the 14 studies which assessed the upper limb strength in subjects with stroke with portable dynamometers and provided information regarding the subject's positioning or the data collection protocol

(To be continued)

\begin{tabular}{|c|c|c|c|}
\hline Study & Muscular group & Subjects' position & Protocol \\
\hline $\begin{array}{l}\text { Bohannon } \\
\text { (24) }\end{array}$ & $\begin{array}{l}\text { Wrist and elbow flexors/ } \\
\text { extensors; } \\
\text { shoulder internal/external } \\
\text { rotators, abductors/ } \\
\text { adductors }\end{array}$ & $\begin{array}{l}\text { Supine, wrist and elbow flexion/extension, } \\
\text { shoulder internal/external rotation: upper } \\
\text { limb next to the body and elbow flexed at } \\
90^{\circ} \text {; shoulder abduction/adduction: elbow } \\
\text { extended and shoulder abducted at } 45^{\circ} \text {. } \\
\text { Manual stabilization next to the evaluated } \\
\text { segment }\end{array}$ & $\begin{array}{l}\text { Three trials, contractions of } 4 \\
\text { to } 5 \text { s, rest intervals between } 10 \\
\text { and } 30 \text { s }\end{array}$ \\
\hline $\begin{array}{l}\text { Bohannon } \\
\text { et al. (82) }\end{array}$ & $\begin{array}{l}\text { Wrist and elbow flexors/ } \\
\text { extensors; shoulder } \\
\text { internal/external rotators, } \\
\text { abductors/adductors, } \\
\text { flexors/extensors }\end{array}$ & $\begin{array}{l}\text { Supine, tested segment without the } \\
\text { interference of gravity and in the middle of } \\
\text { range of motion }\end{array}$ & Same as above \\
\hline $\begin{array}{l}\text { Bohannon } \\
\text { et al. (25) }\end{array}$ & $\begin{array}{l}\text { Wrist extensors; elbow } \\
\text { flexors/extensors; } \\
\text { shoulder internal/ external } \\
\text { rotators, abductors, and } \\
\text { flexors/extensors }\end{array}$ & $\begin{array}{l}\text { Supine, tested segment without the } \\
\text { interference of gravity and in the middle of } \\
\text { range of motion }\end{array}$ & Same as above \\
\hline $\begin{array}{l}\text { Bohannon } \\
\text { et al. (26) }\end{array}$ & $\begin{array}{l}\text { Wrist extensors; elbow } \\
\text { flexors, and shoulder } \\
\text { external rotators }\end{array}$ & $\begin{array}{l}\text { Supine, tested segment without the } \\
\text { interference of gravity and the middle of } \\
\text { range of motion, described by Bohannon } \\
\text { (24) }\end{array}$ & $\begin{array}{l}\text { One trial, contractions of } 4 \\
\text { to } 5 \mathrm{~s}\end{array}$ \\
\hline
\end{tabular}


Table 4 - Data extraction of the 14 studies which assessed the upper limb strength in subjects with stroke with portable dynamometers and provided information regarding the subject's positioning or the data collection protocol

(To be continued)

\begin{tabular}{|c|c|c|c|}
\hline Study & Muscular group & Subjects' position & Protocol \\
\hline $\begin{array}{l}\text { Riddle } \\
\text { et al. (83) }\end{array}$ & $\begin{array}{l}\text { Wrist and elbow flexors/ } \\
\text { extensors; shoulder } \\
\text { internal/external rotators }\end{array}$ & Supine (24) & $\begin{array}{l}\text { Three trials, contractions of } 4 \\
\text { to } 6 \mathrm{~s} \text {, rest intervals of } 10 \text { to } \\
30 \text { s }\end{array}$ \\
\hline $\begin{array}{l}\text { Bohannon } \\
\text { et al. (84) }\end{array}$ & Elbow flexors & $\begin{array}{l}\text { Supine, upper limb extended, } 90^{\circ} \text { of elbow } \\
\text { flexion, } 30^{\circ} \text { of shoulder abduction, forearm } \\
\text { at supine position }\end{array}$ & $\begin{array}{l}\text { Four trials, contractions of } 4 \text { to } \\
5 \mathrm{~s} \text {, rest intervals of } 10 \mathrm{~s}\end{array}$ \\
\hline Bohannon et al. (85) & Elbow flexors & $\begin{array}{l}\text { Supine, elbow flexed at } 90^{\circ} \text {, shoulder } \\
\text { stabilization }\end{array}$ & $\begin{array}{l}\text { Two trials, contractions of } 4 \\
\text { to } 5 \mathrm{~s}\end{array}$ \\
\hline Bohannon (63) & $\begin{array}{l}\text { Elbow flexors and } \\
\text { shoulder abductors }\end{array}$ & $\begin{array}{l}\text { Supine, elbow flexed at } 90^{\circ} \text { and shoulder } \\
\text { at } 45^{\circ}\end{array}$ & $\mathrm{NI}$ \\
\hline $\begin{array}{l}\text { Bohannon } \\
\text { et al. (86) }\end{array}$ & $\begin{array}{l}\text { Wrist extensors, elbow } \\
\text { flexors, and shoulder } \\
\text { abductors }\end{array}$ & $\begin{array}{l}\text { Supine, tested segment without the } \\
\text { interference of gravity and in the middle } \\
\text { of the range of motion, wrist extension: } \\
\text { shoulder in neutral, elbow flexed at } 90^{\circ} \text {, } \\
\text { wrist in neutral and fingers relaxed. } \\
\text { Stabilization: distal forearm; elbow flexion: } \\
\text { shoulder in neutral, elbow flexed at } 90^{\circ} \text {, } \\
\text { forearm in supine. Stabilization: upper arm } \\
\text { or shoulder; shoulder abduction: shoulder } \\
\text { abducted at } 45^{\circ} \text { and elbow extended. } \\
\text { Stabilization: top of shoulder }\end{array}$ & $\mathrm{NI}$ \\
\hline $\begin{array}{l}\text { Andrews } \\
\text { et al. (27) }\end{array}$ & $\begin{array}{l}\text { Wrist extensors, elbow } \\
\text { flexors, and shoulder } \\
\text { abductors }\end{array}$ & $\begin{array}{l}\text { Supine, tested segment without the } \\
\text { interference of gravity, wrist extensors: } \\
\text { shoulder in neutral, elbow flexed at } 90^{\circ} \text {, } \\
\text { and fingers relaxed. Stabilization: distal } \\
\text { forearm, elbow flexors: elbow flexed at } \\
90^{\circ} \text {, forearm in supine. Stabilization: upper } \\
\text { arm or shoulder; elbow extensors: elbow } \\
\text { flexed at } 90^{\circ} \text {. Stabilization: anterior part of } \\
\text { the shoulder or arm; shoulder abductors: } \\
\text { shoulder abducted at } 45^{\circ} \text { and elbow } \\
\text { extended. Stabilization: shoulder }\end{array}$ & $\begin{array}{l}\text { Two trials, contractions of } 3 \text { to } \\
4 \mathrm{~s} \text {, rest intervals of } 1 \text { to } 2 \mathrm{~min}\end{array}$ \\
\hline Byl et al. (47) & $\begin{array}{l}\text { Wrist extensors, elbow } \\
\text { flexors, and shoulder } \\
\text { flexors }\end{array}$ & $\begin{array}{l}\text { Supine or sitting; wrist extensors: arm on } \\
\text { the table, forearm in prone, and wrist in } \\
\text { neutral. Stabilization: distal forearm; elbow } \\
\text { flexors: elbow flexed at about } 90^{\circ} \text {, forearm } \\
\text { in supine. Stabilization: under the elbow, } \\
\text { shoulder flexors: shoulder flexed and } \\
\text { internally rotated, elbow flexed and forearm } \\
\text { in supine. Stabilization at the trunk }\end{array}$ & $\mathrm{NI}$ \\
\hline Bohannon (70) & $\begin{array}{l}\text { Elbow flexors and } \\
\text { shoulder abductors }\end{array}$ & $\begin{array}{l}\text { Supine: elbow flexors: elbow flexed at } 90^{\circ} \\
\text { and forearm in supine; shoulder abuctors: } \\
\text { shoulder abducted at } 45^{\circ} \text { and elbow } \\
\text { extended }\end{array}$ & $\begin{array}{l}\text { One trial, contractions of } 4 \text { to } \\
5 \mathrm{~s} \text {, rest intervals of } 1 \mathrm{~min}\end{array}$ \\
\hline
\end{tabular}


Table 4 - Data extraction of the 14 studies which assessed the upper limb strength in subjects with stroke with portable dynamometers and provided information regarding the subject's positioning or the data collection protocol

(Conclusion)

\begin{tabular}{|c|c|c|c|}
\hline Study & Muscular group & Subjects' position & Protocol \\
\hline $\begin{array}{l}\text { Beebe } \\
\text { et al. (55) }\end{array}$ & $\begin{array}{l}\text { Index finger, wrist, elbow, } \\
\text { and shoulder flexors and } \\
\text { extensors }\end{array}$ & $\begin{array}{l}\text { Supine, tested segment without the } \\
\text { interference of gravity; forefinger flexors/ } \\
\text { extensors: Nl; wrist flexors: Nl; wrist } \\
\text { extensors: shoulder in neutral, elbow flexed } \\
\text { at } 90^{\circ} \text {, and fingers relaxed. Stabilization: } \\
\text { distal forearm; elbow flexors: elbow flexed } \\
\text { at } 90^{\circ} \text {, forearm in supine. Stabilization: } \\
\text { anterior part of the shoulder or arm; } \\
\text { shoulder flexors: shoulder flexed at } 90^{\circ} \\
\text { and elbow extended. Stabilization: axillary } \\
\text { region, shoulder extensors: shoulder flexed } \\
\text { at } 90^{\circ} \text {, elbow flexed. Stabilization: shoulder }\end{array}$ & $\mathrm{NI}$ \\
\hline $\begin{array}{l}\text { Beebe } \\
\text { et al. (76) }\end{array}$ & $\begin{array}{l}\text { Index finger, wrist, elbow, } \\
\text { and shoulder flexors and } \\
\text { extensors }\end{array}$ & Same as above & $\mathrm{NI}$ \\
\hline
\end{tabular}

Note: $\mathrm{Nl}=$ not informed. The assessment of strength was performed with isometric contractions in all studies.

Few studies reported the use of visual or verbal feedback to motivate the participants during the performance of maximal isometric contractions: only two studies that evaluated the strength of the UL muscles $(26,84)$ reported some stimulus. The demonstration and familiarization with the procedures were also rarely reported: four studies related to UL muscles $(24-26,82)$, one related to handgrip (28), and one related to pinch strength (81) reported that demonstration procedures were carried out and familiarization occurred in only one UL study (27) and two of handgrip $(28,62)$.

Table 5 - Results of the nine studies which assessed the measurement properties of the portable dynamometers

(To be continued)

\begin{tabular}{|c|c|c|c|c|}
\hline Study & Sample & Muscular group & $\begin{array}{l}\text { Measurement } \\
\text { property }\end{array}$ & Results \\
\hline $\begin{array}{l}\text { Bohannon } \\
(24)\end{array}$ & $\begin{array}{l}n=16, \text { aged between } \\
17 \text { and } 82 \text { years }\end{array}$ & $\begin{array}{l}\text { Wrist and elbow flexors/ } \\
\text { extensors, shoulder } \\
\text { internal/external } \\
\text { rotators and abductors/ } \\
\text { adductors }\end{array}$ & Test-retest reliability & $0.95 \leq r \leq 0.99$ \\
\hline $\begin{array}{l}\text { Bohannon } \\
\text { et al. (25) }\end{array}$ & $\begin{array}{l}\mathrm{n}=42 \text {, male and } \\
\text { female, ages between } \\
22 \text { e } 84 \text { years, time } \\
\text { since the onset of stroke } \\
\text { between } 9 \text { and } 233 \text { days }\end{array}$ & $\begin{array}{l}\text { Wrist extensors; elbow } \\
\text { flexors/extensors; } \\
\text { shoulder internal/ } \\
\text { external rotators, } \\
\text { adductors, and flexors/ } \\
\text { extensors }\end{array}$ & Test-retest reliability & $r^{2} \geq 0.88$ \\
\hline $\begin{array}{l}\text { Bohannon } \\
\text { et al. (26) }\end{array}$ & $\begin{array}{l}n=21, \text { male and } \\
\text { female }\end{array}$ & $\begin{array}{l}\text { Wrist extensors, elbow } \\
\text { flexors, and shoulder } \\
\text { external rotators }\end{array}$ & Inter-rater reliability & $0.88 \leq r \leq 0.94$ \\
\hline
\end{tabular}


Table 5 - Results of the nine studies which assessed the measurement properties of the portable dynamometers

(Conclusion)

\begin{tabular}{|c|c|c|c|c|}
\hline Study & Sample & Muscular group & $\begin{array}{l}\text { Measurement } \\
\text { property }\end{array}$ & Results \\
\hline Riddle et al. (83) & $\begin{array}{l}\mathrm{n}=31 \text {, mean age of } \\
54.6 \pm 18.1 \text { years, time } \\
\text { since the onset of stroke } \\
\text { between } 5 \text { and } 150 \text { days }\end{array}$ & $\begin{array}{l}\text { Wrist flexors and } \\
\text { extensors, elbow flexors } \\
\text { and extensors, and } \\
\text { shoulder internal and } \\
\text { external rotators }\end{array}$ & $\begin{array}{l}\text { Test-retest and inter- } \\
\text { rater reliabilities }\end{array}$ & $\begin{array}{l}\text { Test-retest } \\
0.91 \leq r \leq 0.99 \text {; } \\
\text { ICC: } 0.93-0.98 \\
\text { Inter-rater } \\
0.92 \leq r \leq 0.98 \text {; } \\
\text { ICC: } 0.90-0.98\end{array}$ \\
\hline $\begin{array}{l}\text { Bohannon } \\
\text { et al. (85) }\end{array}$ & $n=23$ & Elbow flexors & Inter-rater reliability & $\mathrm{ICC}=0.99$ \\
\hline Bohannon (63) & $\begin{array}{l}n=10, \text { male and } \\
\text { female, ages between } \\
46 \text { and } 81 \text { years, time } \\
\text { since the onset of stroke } \\
\text { between } 2 \text { and } 10 \text { days }\end{array}$ & $\begin{array}{l}\text { Elbow flexors, shoulder } \\
\text { abductors, and grip } \\
\text { strength }\end{array}$ & Test-retest reliability & $0.95 \leq r_{s} \leq 0.96$ \\
\hline $\begin{array}{l}\text { Bohannon } \\
\text { et al. (42) }\end{array}$ & $\begin{array}{l}n=11 \text { male and } \\
\text { female, mean age of } \\
67.4 \pm 10.2 \text { years, time } \\
\text { since the onset of stroke } \\
\text { of } 14.2 \pm 11.5 \text { days }\end{array}$ & $\begin{array}{l}\text { Anterior and lateral trunk } \\
\text { flexors }\end{array}$ & Inter-rater reliability & $\mathrm{ICC}=0.80-0.82$ \\
\hline Boissy et al. (9) & $\begin{array}{l}n=15, \text { male and } \\
\text { female, ages between } \\
29 \text { and } 65 \text { years }\end{array}$ & Grip & Test-retest reliability & $\mathrm{ICC}=0.91$ \\
\hline Hammer et al. (28) & $\begin{array}{l}n=18 \text {, male and } \\
\text { female, ages between } \\
38 \text { and } 63 \text { years, time } \\
\text { since the onset of stroke } \\
\text { between } 2 \text { and } 25 \text { weeks }\end{array}$ & Grip & Test-retest reliability & $\mathrm{C}_{\mathrm{R}}=48.2 \mathrm{~N}$ \\
\hline
\end{tabular}

Note: $r=$ Pearson correlation coefficients; $r^{2}=$ coefficients of determination; ICC = Intra-class correlation coefficient; $r_{\mathrm{s}}=$ Spearman correlation coefficients; $C_{R}=$ reproducibility coefficient. The assessment of strength was performed with isometric contractions in all studies.

\section{Discussion}

The aim of this study was to investigate whether there were standardized protocols for the use of portable dynamometers for the assessment of strength of the trunk and UL muscles, including handgrip and pinch strength in subjects with stroke, as well as to verify which measurement properties were investigated. The majority of the studies assessed handgrip, followed by elbow flexors, wrist extensors, elbow extensors and lateral pinch strength. In addition, adults and elderly subjects at the acute, sub-acute, and chronic phases after stroke were included, thus covering a large sample variability. Most studies described the positioning of the subjects and/or the data collection protocols, however, without standardized procedures. The only investigated measurement property was reliability, with excellent results in most studies.

The muscular groups of the UL, which were evaluated with portable dynamometry are often impaired in stroke subjects $(12,25,27)$ and are important for the performance of functional activities $(7,54,85)$. However, despite the extensive search, only three studies related to the strength of the trunk muscles in stroke 
subjects with portable dynamometry, but they did not include subjects at the chronic phase nor evaluated the strength of the trunk extensor and rotator muscles.

Although weakness of the trunk muscles were already identified in stroke $(14,42,88,89)$, possibly the strength of the trunk muscles has been poorly evaluated, because the weakness is most remarkable in the upper and lower limb muscles, especially those contralateral to the side of the brain injury $(14,42)$. The nerve supply of the trunk muscles provided by both cerebral hemispheres (90), which may justify less remarkable impairment of this segment, compared to limbs (15). Moreover, according to Bohannon (14), the recovery of the strength of the trunk muscles follows the time of the onset of stroke (14), and therefore, impairments of the trunk muscles are most evident at the acute and sub-acute phases after stroke (15). In addition, according to Bohannon (14), the greatest recovery of strength after stroke was found for the anterior trunk flexors, which is usually the most affected muscular group. Possibly, these are the reasons that the studies that assessed the strength of the trunk muscles included subjects at the acute phases and the assessment of anterior trunk flexors. Within this context, it is important to note that subjects at the chronic phases also demonstrate weakness of the trunk muscles, which is associated with functional limitations $(15$, 91). Furthermore, this weakness is observed not only on the anterior trunk flexors, but also on the extensors and rotators $(88,89)$.

All trunk muscles play an important role in supporting the body during antigravity postures and in stabilizing the proximal body during functional movements of the limbs (92). Adequate function of these muscles is crucial for balance, transfers, gait, and other functional activities (15), providing stability and mobility for the performance of daily tasks (93). Therefore, the assessment of the strength of the trunk muscles is essential $(15,94)$ for all subjects affected by stroke, because they have significant impairments of these muscles $(15,42)$.

Despite the widespread use of portable dynamometry for the assessment of UL muscles, including handgrip and pinch strength, only nine studies investigated its measurement properties with stroke subjects. All studies reported data related to reliability, which was found to be excellent in most of them. Test-retest or intra-rater reliability was the most investigated property, probably by the fact that repeated measures by the same examiner are easily obtained, and are commonly used within clinical settings, where the measures of the same professional are compared before and after an intervention, for example. Since the results indicated reliable measures when they are performed by the same examiner, the changes observed in measures performed by the same examiner before and after an intervention, for example, can be attributed to changes obtained with the performed intervention (87).

Most of the studies which investigated reliability, calculated the Pearson correlation coefficients to correlate the measurements obtained in different sessions (defined by the authors as intra-rater or test-retest reliability) or by different examiners (inter-rater reliability). However, this statistical test only evaluates the degree of associations between the measures, without considering the levels of agreement and, therefore, it is not considered the most adequate method for the assessment of reliability (83, 87). On the other hand, intra-class correlation coefficients (ICCs) are mostly recommended to assess reliability, since they reflect both the associations and the agreement between two or more measures $(83,87)$. All four studies that used ICCS, reported coefficients 0.80 , which are indicative of excellent reliability.

Another important issue to be considered is that the terminology used in the studies to specify the types of similar reliability varied: test-retest, intra-, inter-session, and intra-rater reliability. Test-retest reliability is used to determine whether an instrument or test provides consistent measures, keeping all other measurement conditions as constant, as possible (87). In the case of portable dynamometry assessment, in which the resistance exerted by the examiners is critical, it is necessary to guarantee that their measures are reliable. As pointed out by Portney and Watkins (87), "in a test-retest situation, when a rater's skill is relevant to the accuracy of the test, intra-rater reliability and test-retest reliability are essentially the same estimate. The effects of rater and the test cannot be separated out".

The results of this review found that validity was not investigated for portable dynamometer with stroke subjects. Despite the fact that portable dynamometers are devices with adequate face validity for the measurement of strength, studies were found that compared the measurements provided by the portable dynamometers with those obtained with isokinetic dynamometers, which are considered the gold standard for the assessment of strength (37). These studies, 
which evaluated various muscular groups and subjects with different health conditions, reported good concurrent criterion-related validity for the portable dynamometry. However, they did not assessed the strength of the UL and trunk muscles nor stroke subjects (37). Considering that the subjects' characteristics could influence the measurements obtained with these devices, such as difficulty in understanding the commands (2) and recruiting motor units for the generation of strength (95), it becomes necessary to investigate the concurrent criterion-related validity of the portable dynamometry for the assessment of these muscular groups with this population.

Amongst the muscular groups commonly evaluated with portable dynamometers in stroke subjects, the measurement properties of the pinch strength were not investigated. According to Araújo et al. (35), pinch strength measures are related to dexterity and accuracy of the movements. Faria-Fortini et al. (7) found that impairments of the lateral pinch strength in subjects with stroke were associated with deficits in functional activities. Thus, the measurement properties of the portable dynamometers for the assessment of strength in this population should be investigated. To recommend the use of an instrument in a given population, such as stroke subjects, for the assessment of a specific muscular group, it is necessary that its measurement properties be established, considering the context of interest, such as the population and/or muscular groups, for example. The validity and reliability of a method and/ or a measurement instrument is not guaranteed if they are used within contexts, which are different from those for which they were developed $(87,96)$.

Most of the studies performed bilateral measures of the strength of the UL, including handgrip strength. The loss of strength of the paretic side is a common impairment in stroke subjects. However, weakness is also commonly observed on the non-paretic side $(60,86)$. Due to the decrease in overall strength in subjects affected by stroke, it is necessary that these measures are obtained bilaterally $(86,97)$.

The positioning for the assessment of handgrip and pinch strength, in most studies, followed the recommendation of the American Society of Hand Therapists, with the participant seated, shoulder adducted, elbow flexed to $90^{\circ}$, forearm in neutral position, wrist between $0^{\circ}$ and $30^{\circ}$ of extension, and $0^{\circ}$ and $15^{\circ}$ of ulnar deviation $(29-31,63,70,72,76$, 77). Most studies that evaluated the trunk muscles, handgrip, and pinch strength adopted the sitting position, while the supine position was further used to evaluate the muscles of the other UL muscles. Most studies that evaluated the strength of other UL muscles placed the limb in a position to avoid the influence of the gravity. The MMT, which is the most common method for the assessment of strength within clinical settings usually follows the position recommended by Kendall et al. (98). Only one study (47) cited the same position described by Kendall et al. (98) and did not avoid the influence of gravity to test the strength of the UL muscles. For the assessment of the trunk and UL muscles, the equipment was positioned perpendicular to the evaluated segment and in the case of the UL, in the distal extremity.

The contraction time, which was most used for the UL muscles varied from 4 to 5 seconds $(14,24-26,70$, $82,84,85)$; for the handgrip strength, it was about 10 seconds $(28,65,69)$. Only one study regarding pinch strength described contraction time of 1 to 3 seconds (30), and for the trunk muscles, this time ranged from 3 to 5 seconds $(14,42)$. The time of maximum effort was also quite varied. However, most of the studies included in this review used 4 to 5 seconds, whose values can be used as references.

The rest interval also varied between the studies. The most widely used for the UL muscles was 10 to 30 seconds $(24,25,82,83)$ and for the handgrip strength was the alternate method $(12,68,74)$. Mathiowetz (99) reported that it is not really necessary to extend the rest interval, because the differences between measurements with different rest interval are small. Trossman et al. (100) investigated the effect of rest interval between five trials and did not found significant differences between rest intervals of $60 \mathrm{~s}, 30 \mathrm{~s}$, and 15s. Therefore, rest intervals of $15 \mathrm{~s}$ seem to be sufficient to avoid effects of fatigue.

The scoring method most commonly used to analyze the maximal isometric strength in stroke subjects was the mean of three trials $(9,12,24,25,60,61,65$, $82,83)$. Variations of the scoring were reported in healthy subjects, for example, the use of only one trial, the best value of two or three trials (101). Coldham et al. (101) evaluated handgrip strength in healthy subjects and in subjects who had undergone orthopedic surgery, and reported that the use of only one trial of maximum strength was appropriate, less painful, and as reliable as the mean or the best value of three trials. Similar studies in subjects with stroke are needed to determine if the mean of three trials is the best scoring method. However, none of the studies included in 
this review compared different ways of scoring the measures provided by portable dynamometer (mean of two or three trials, or the value of a single trial).

Few studies reported procedures of demonstration $(24-26,28,81,82)$ and familiarization with the devices and/or with the data collection protocol (27, 28,62 ) or provided stimulation for motivating the participants $(26,84)$ during data collection. These factors may influence the measurements of strength obtained with portable dynamometry. Consistent instructions for performing a standardized protocol could minimize the errors and promote better quality of the measures $(33,102)$. Considering stroke subjects, who show difficulties in achieving contractions, especially on the paretic side $(70,83)$ and in understanding (2), procedures related to demonstration, familiarization, and encouragement are essential to obtain adequate measures of strength.

\section{Final considerations}

Portable dynamometry has been used for the assessment of most muscular groups of the UL in stroke subjects, including handgrip and pinch strength, with large and varied samples. However, the same was not observed for the muscles of the trunk. Most studies provided some information regarding the subjects' positioning and/or data collection protocol, however, without any standardization. Few studies investigated the measurement properties of the portable dynamometer and only reliability was reported, with adequate results in most of the studies. Few studies have reported procedures related to familiarization and/or motivation. No studies were found which investigated the reliability of portable dynamometer for the assessment of pinch strength, neither its validity in subjects with stroke. Thus, there are still important gaps that limit adequate scientific foundation for the clinical decision making regarding the use of portable dynamometer for the assessment of the strength of the UL and trunk muscles in individuals with stroke.

\section{References}

1. Lopez A, Mathers C, Ezzati M, Jamison D, Murray C. Global and regional burden of disease and risk factors, 2001: systematic analysis of population health data. Lancet. 2006;367(9524):1747-57.
2. World Health Organization. Neurological disorders: public health challenges. Geneva: WHO Library Cateloguin-in-Publication Data; 2006.

3. Ada L, Dorsch S, Canning CG. Strengthening interventions increase strength and improve activity after stroke: a systematic review. Aust J Physiother. 2006; 52(4):241-8.

4. Kamper D, Fischer H, Cruz E, Rymer W. Weakness is the primary contributor to finger impairment in chronic stroke. Arch Phys Med Rehabil. 2006;87(9):1262-9.

5. Bohannon RW. Muscle strength and muscle training after stroke. J Rehabil Med. 2007;39(1):14-20.

6. Abe I. Prevalência de acidente vascular cerebral em área de exclusão social na cidade de São Paulo, Brasil: utilizando questionário validado para sintomas [tese]. São Paulo: Universidade de São Paulo; 2010.

7. Faria-Fortini I, Michaelsen S, Cassiano J, TeixeiraSalmela L. Upper extremity function in stroke subjects: relationships between the International Classification of Functioning, Disability, and Health Domains. J Hand Ther. 2011;24(3):257-65.

8. Kwakkel G, Kollen B. Predicting improvement in the upper paretic limb after stroke: a longitudinal prospective study. Restor Neurol Neurosci. 2007; 25(5-6):453-60.

9. Boissy P, Bourbonnais D, Carlotti MM, Gravel D, Arsenault BA. Maximal grip force in chronic stroke subjects and its relationship to global upper extremity function. Clin Rehabil. 1999;13(4):354-62.

10. Mercier C, Bourbounais D. Relative shoulder flexor and handgrip strength is related to upper limb function after stroke. Clin Rehabil. 2004;18(2):215-21.

11. Nascimento L. Desempenho muscular isocinético do complexo do ombro de indivíduos com hemiparesia crônica [dissertação]. Belo Horizonte: Universidade Federal de Minas Gerais; 2011.

12. Sunderland A, Tinson D, Bradley L, Hewer R. Arm function after stroke. An evaluation of grip strength as a measure of recovery and a prognostic indicator. J Neurol Neurosurg Psychiatry. 1989;52(11):1267-72.

13. Harris JE, Eng JJ. Paretic upper-limb strength best explains arm activity in people with stroke. Phys Ther. 2007;87(1):88-97. 
14. Bohannon RW. Recovery and correlates of trunk muscle strength after stroke. Int J Rehabil Res. 1995; 18(2):162-7.

15. Karatas M, Çetin N, Bayramoglu M, Dilek A. Trunk muscle strength in relation to balance and functional disability in unihemispheric stroke patients. Am J Phys Med Rehabil. 2004;83(2):81-7.

16. Oullette MM, LeBrasseur NK, Bean JF, Philips E, Stein J, Frontera WR, et al. High-intensity resistance training improves muscle strength, self-reported function, and disability in long-term stroke survivors. Stroke. 2004;35(6):1404-9.

17. Moraes G, Nascimento L, Glória A, Teixeira-Salmela L, Paiva C, Lopes T, et al. A influência do fortalecimento muscular no desempenho motor do membro superior parético de indivíduos acometidos por Acidente Vascular Encefálico. Acta Fisiatr. 2008;15(4):245-8.

18. Lima N, Rodrigues S, Fillipo T, Oliveira R, Oberg T, Cacho E. Versão brasileira da Escala de Comprometimento do Tronco: um estudo de validade em sujeitos pós-acidente vascular encefálico. Fisioter Pesqui. 2008;15(3):248-53.

19. Durfee W, Iaizzo P. Rehabilitation and muscle testing. In: Webster J, editor. Encyclopedia of medical devices and instrumentation. 2. ed. Minnesota: Wiley Online Library; 2006.

20. Wadsworth CT, Krishnan R, Sear M, Harrold J, Nielsen DH. Intrarater reliability of manual muscle testing and hand-held dynametric muscle testing. Phys Ther. 1987;67(9):1342-7.

21. Sisto S, Dyson-Hudson T. Dynamometry testing in spinal cord injury. J Rehabil Res Dev. 2007;44(1):123-36.

22. Morris S, Dodd K, Morris M. Reliability of dynamometry to quantify isometric strength following traumatic brain injury. Brain Inj. 2008;22(13-14):1030-7.

23. Bohannon RW. Interrelationships of trunk and extremity muscle strengths and body awareness following unilateral brain lesions. Percept Mot Skills. 1991; 73(3 Pt 1):1016-8.

24. Bohannon RW. Test-retest reliability of hand-held dynamometry during a single session of strength assessment. Phys Ther. 1986;66(2):206-9.
25. Bohannon RW, Smith MB. Assessment of strength deficits in eight paretic upper extremity muscle groups of stroke patients with hemiplegia. Phys Ther. 1987; 67(4):522-5.

26. Bohannon RW, Andrews AW. Interrater reliability of hand-held dynamometry. Phys Ther. 1987; 67(6):931-3.

27. Andrews AW, Bohannon RW. Short-term recovery of limb muscle strength after acute stroke. Arch Phys Med Rehabil. 2003;84(1):125-30.

28. Hammer A, Lindmark B. Test-retest intra-rater reliability of grip force in patients with stroke. J Rehabil Med. 2003;35(4):189-94.

29. Conforto A, Kaelin-Lang A, Cohen L. Increase in hand muscle strength of stroke patients after somatosensory stimulation. Ann Neurol. 2002;51(1):122-5.

30. Hummel F, Voller B, Celnik P, Floel A, Giraux P, Gerloff $\mathrm{C}$, et al. Effects of brain polarization on reaction times and pinch force in chronic stroke. BMC Neurosci. 2006;7:73.

31. Ploughman M, Shears J, Hutchings L, Osmond M. Constraint-induced movement therapy for severe upperextremity impairment after stroke in an outpatient rehabilitation setting: a case report. Physiother Can. 2008;60(2):161-70.

32. Andrews AW, Thomas MW, Bohannon RW. Normative values for isometric muscle force measurements obtained with hand-held dynamometers. Phys Ther. 1996;76(3):248-59.

33. Figueiredo IM, Sampaio RF, Mancini MC, Silva F, Souza MAP. Teste de força de preensão utilizando o dinamômetro Jamar. Acta Fisiatr. 2007;14(2):104-10.

34. Bohannon RW. Adequacy of hand-grip dynamometry for characterizing upper limb strength after stroke. Isokinet Exerc Sci. 2004;12(4):263-5.

35. Araújo MP, Araújo PMP, Caporrino FA, Faloppa F, Albertoni WM. Estudo populacional das forças das pinças polpa-apolpa, trípode e lateral. Rev Bras Ortop. 2002;37(11-12):496-504.

36. Gonçalves GH, Gomes DA, Teixeira MDM, Shimano SGN, Shimano AC, Fonseca MCR. Força de preensão palmar e pinça digital em diferentes grupos de pilotos da Academia da Força Aérea brasileira. Fisioter Pesqui. 2010;17(2):141-6. 
37. Stark T, Walker B, Phillips J, Fejer R, Beck R. Handheld dynamometry correlation with the gold standard isokinetic dynamometry: a systematic review. PM R. 2011;3(5):472-9.

38. Wu H, Tang J, Lin X, Lau J, Leung P, Woo J, et al. Acupuncture for stroke rehabilitation. Cochrane Database Syst Rev. 2006;(3):CD004131.

39. Moher D, Liberati A, Tetzlaff J, Altman DG; PRISMA Group. Preferred reporting items for systematic reviews and meta-analyses: the PRISMA statement. Int J Surg. 2010;8(5):336-41.

40. Puga VOO, Lopes AD, Costa LOP. Avaliação das adaptações transculturais e propriedades de medida de questionários relacionados às disfunções do ombro em língua portuguesa: uma revisão sistemática. Rev Bras Fisioter. 2012;16(2):85-93.

41. Faria CDCM, Saliba VA, Teixeira-Salmela LF. Musculoskeletal biomechanics in sit-to-stand and stand-to-sit activities with stroke subjects: a systematic review. Fisioter Mov. 2010; 23(1):35-52.

42. Bohannon RW, Cassidy D, Walsh S. Trunk muscle strength is impaired multidirectionally after stroke. Clin Rehabil. 1995;9(1):47-51.

43. Wade DT, Langton-Hewer R, Wood VA, Skilbeck C, Ismail $\mathrm{H}$. The hemiplegic arm after stroke: measurement and recovery. J Neurol Neurosurg Psychiatry. 1983;46(6):521-4.

44. Kraft G, Fitts S, Hammond M. Techniques to improve function of the arm and hand in chronic hemiplegia. Arch Phys Med Rehabil. 1992;73(3):220-7.

45. Taub E, Miller N, Novack T, Cook III E, Fleming W, Nepomuceno C, et al. Technique to improve chronic motor deficit after stroke. Arch Phys Med Rehabil. 1993;74(4):347-54.

46. Whitall J, McCombe Waller S, Silver K, Macko R. Repetitive bilateral arm training with rhythmic auditory cueing improves motor function in chronic hemiparetic stroke. Stroke. 2000;31(10):2390-5.

47. Byl N, Roderick J, Mohamed O, Hanny M, Kotler J, Smith A, et al. Effectiveness of sensory and motor rehabilitation of the upper limb following the principles of neuroplasticity: patients stable poststroke. Neurorehabil Neural Repair. 2003;17(3):176-91.
48. McCombe Waller S, Whitall J. Hand dominance and side of stroke affect rehabilitation in chronic stroke. Clin Rehabil. 2005;19(5):544-51.

49. Desrosiers J, Bourbounais D, Bravo G, Roy P, Guay M. Performance of the 'unaffected' upper extremity of elderly stroke patients. Stroke. 1996;27(9):1564-70.

50. Levy C, Nichols D, Schmalbrock P, Keller P, Chakeres D. Functional MRI evidence of cortical reorganization in upper-limb stroke hemiplegia treated with constraintinduced movement therapy. Am J Phys Med Rehabil. 2001;80(1):4-12.

51. Jack D, Boian R, Merians A, Tremaine M, Burdea G, Adamovich $\mathrm{S}$, et al. Virtual reality-enhanced stroke rehabilitation. IEEE Trans Neural Syst Rehabil Eng. 2001;9(3):308-18.

52. McAniff C, Bohannon RW. Validity of grip strength dynamometry in acute rehabilitation. J PhysTher Sci. 2002;14(1):41-6.

53. Duncan P, Studenski S, Richards L, Gollub S, Lai SM, Reker D, et al. Randomized clinical trial of therapeutic exercise in subacute stroke. Stroke. 2003; 34(9):2173-80.

54. Lang CE, Beebe J. Relating movement control at 9 upper extremity segments to loss of hand function in people with chronic hemiparesis. Neurorehabil Neural Repair. 2007;21(3):279-91.

55. Beebe J, Lang CE. Absence of a proximal to distal gradient of motor deficits in the upper extremity early after stroke. Clin Neurophysiol. 2008;119(9):2074-85.

56. Trickbroom G, Byrnes M, Archer S, Mastaglia F. Motor outcome after subcortical stroke: MEPs correlate with hand strength but not dexterity. Clin Neurophysiol. 2002;113(12):2025-9.

57. Connelly L, Jia Y, Toro M, Stoykov M, Kenyon R, Kamper DG. A pneumatic glove and immersive virtual reality environment for hand rehabilitative training after stroke. IEEE Trans Neural Syst Rehabil Eng. 2010; 18(5):551-9.

58. Triandafilou K, Ochoa J, Kang X, Fischer HC, Stoykov ME, Kamper DG. Transient impact of prolonged versus repetitive stretch on hand motor control in chronic stroke. Top Stroke Rehabil. 2011;18(4):316-24. 
59. Stoykov M, Lewis G, Corcos D. Comparison of bilateral and unilateral training for upper extremity hemiparesis in stroke. Neurorehabil Neural Repair. 2009; 23(9):945-53.

60. Jones R, Donaldson I, Parkin P. Impairment and recovery of ipsilateral sensory-motor function following unilateral cerebral infarction. Brain. 1989;112(Pt 1):113-32.

61. van Deusen J, Shalik L, Harlowe D. Construct validation of an acute care occupational therapy cerebral vascular accident assessment tool. Can J Occup Ther. 1990;57(3):155-9.

62. Robinson L, Fitts S, Kraft G. Laterality of performance in fingertapping rate and grip strength by hemisphere of stroke and gender. Arch Phys Med Rehabil. 1990;71(9):695-8.

63. Bohannon RW. Consistency of paretic upper extremity motor performance soon after stroke. J Phys Ther Sci. 1995;7(2):49-51.

64. Marque P, Felez A, Puel M, Demonet J, Guiraud-Chaumeil B, Roques C, et al. Impairment and recovery of left motor function in patients with right hemiplegia. J Neurol Neurosurg Psychiatry. 1997;62(1):77-81.

65. Bhakta B, Cozens J, Chamberlain M, Bamford J. Quantifying associated reactions in the paretic arm in stroke and their relationship to spasticity. Clin Rehabil. 2001; 15(2):195-206.

66. Merians A, Jack D, Boian R, Tremaine M, Burdea G, Adamovich S, et al. Virtual reality-augmented rehabilitation for patients following stroke. Phys Ther. 2002;82(9):898-915.

67. Pandyan A, Cameron M, Powell J, Stott D, Granat M. Contractures in the post-stroke wrist: a pilot study of its time course of development and its association with upper limb recovery. Clin Rehabil. 2003;17(1):88-95.

68. Dijkerman H, Ietswaart M, Johnston M, MacWalter R. Does motor imagery training improve hand function in chronic stroke patients? A pilot study. Clin Rehabil. 2004;18(5):538-49.

69. Broeren J, Rydmark M, Sunnerhagen K. Virtual reality and haptics as a training device for movement rehabilitation after stroke: a single-case study. Arch Phys Med Rehabil. 2004;85(8):1247-50.
70. Bohannon RW. Adequacy of simple measures for characterizing impairment in upper limb strength following stroke. Percept Mot Skills. 2004;99(3 Pt 1):813-7.

71. Suputtitada A, Suwanwela N, Tumvitee S. Effectiveness of constraint-induced movement therapy in chronic stroke patients. J Med Assoc Thai. 2004;87(12):1482-90.

72. Wolf SL, Winstein C, Miller J, Taub E, Uswatte G, Morris D, et al. Effect of constraint-induced movement therapy on upper extremity function 3 to 9 months after stroke: the EXCITE randomized clinical trial. JAMA. 2006;296(17):2095-104.

73. Restemeyer C, Weiller C, Liepert J. No effect of a levodopa single dose on motor performance and motor excitability in chronic stroke. A double-blind placebocontrolled cross-over pilot study. Restor Neurol Neurosci. 2007;25(2):143-50.

74. Gosselin S, Desrosiers J, Corriveau H, Hébert R, Rochette A, Provencher V, et al. Outcomes during and after inpatient rehabilitation: comparison between adults and older adults. J Rehabil Med. 2008;40(1):55-60.

75. Kang H, Sok S, Kang J. Effects of meridian acupressure for stroke patients in Korea. J Clin Nurs. 2009; 18(15):2145-52.

76. Beebe J, Lang CE. Relationships and responsiveness of six upper extremity function tests during the first six months of recovery after stroke. J Neurol Phys Ther. 2009;33(2):96-103.

77. Bohannon RW. Grip strength impairments among older adults receiving physical therapy in a homecare setting. Percept Mot Skills. 2010;111(3):761-4.

78. Burdea G, Cioi D, Martin J, Fensterheim D, Holenski M. The Rutgers Arm II rehabilitation system - a feasibility study. IEEE Trans Neural Syst Rehabil Eng. 2010;18(5):505-14.

79. Lomarev M, Kim D, Richardson S, Voller B, Hallett M. Safety study of high-frequency transcranial magnetic stimulation in patients with chronic stroke. Clin Neurophysiol. 2007;118(9):2072-5.

80. McDonnell M, Hillier S, Miles T, Thompson P, Ridding M. Influence of combined afferent stimulation and taskspecific training following stroke: a pilot randomized controlled trial. Neurorehabil Neural Repair. 2007;21(5):435-43. 
81. Klaiput A, Kitisomprayoonkul W. Increased pinch strength in acute and subacute stroke patients after simultaneous median and ulnar sensory stimulation. Neurorehabil Neural Repair. 2009;23(4):351-6.

82. Bohannon RW, Smith MB. Upper extremity strength deficits in hemiplegic stroke patients: relationship between admission and discharge assessment and time since onset. Arch Phys Med Rehabil. 1987;68(3):155-7.

83. Riddle D, Finucane S, Rothstein J, Walker M. Intrasession and intercession reliability of hand-held dynamometer measurements taken on brain-damaged patients. Phys Ther. 1989;69(3):182-94.

84. Bohannon RW, Andrews AW. Influence of head-neck rotation on static elbow flexion force of paretic side in patients with hemiparesis. Phys Ther. 1989; 69(2):135-7.

85. Bohannon RW, Warren M, Cogman K. Motor variables correlated with the hand-to-mouth maneuver in stroke patients. Arch Phys Med Rehabil. 1991;72(9):682-4.

86. Bohannon RW, Andrews AW. Limb muscle strength is impaired bilaterally after stroke. J Phys Ther Sci. 1995;7(1):1-7.

87. Portney LG, Watkins MP. Foundations of clinical research: applications to practice. 2. ed. New Jersey: Prentice-Hall; 2000.

88. Tanaka S, Hachisuska K, Ogata H. Muscle strength of trunk flexion-extension in post-stroke hemiplegic patients. Am J Phys Med Rehabil. 1998;77(4):288-290.

89. Tanaka S, Hachisuska K, Ogata H. Trunk rotatory muscle performance in post-stroke hemiplegic patients. Am J Phys Med Rehabil. 1997;76(5):366-369.

90. Taoka M, Toda T, Iwamura Y: Representation of the midline trunk, bilateral arms, and shoulders in the monkey postcentral somatosensory cortex. Exp Brain Res. 1998;123(3):315-22.

91. Castellassi CS, Ribeiro EAF, Fonseca VC, Beinotti F, Oberg TD, Lima NMFV. Confiabilidade da versão brasileira da escala de deficiências de tronco em hemiparéticos. Fisioter Mov. 2009;22(2):189-99.

92. Tsuji T, Liu M, Hase K, Masakado Y, Chino N. Trunk muscles in persons with hemiparetic stroke evaluated with computed tomography. J Rehabil Med. 2003; 35(4):184-8.
93. Aguiar P, Rocha T, Oliveira E. Escalas de controle de tronco como prognóstico funcional em pacientes após acidente vascular encefálico. Acta Fisiatr. 2008; 15(3):160-4.

94. Wang C, Hsueh I, Sheu CF, Hsieh CL. Discriminative, predictive, and evaluative properties of a trunk control measure in patients with stroke. Phys Ther. 2005; 85(9):887-94.

95. Ng SSM, Shepherd RB. Weakness in patients with stroke: implications for strength training in neurorehabilitation. Phys Ther Rev. 2000;5(4):227-38.

96. Streiner DL, Norman GR. Health measurment scales: a pratical guide do their development and use. 4. ed. New York: Oxford; 2008.

97. Andrews AW, Bohannon RW. Distribution of muscle strength impairments following stroke. Clin Rehabil. 2000;14(1):79-87.

98. Kendall FP, McCreary EK, Provance PG, Rodgers MM, Romani WA. Músculos: provas e funções. 5. ed. Barueri: Manole; 2007.

99. Mathiowetz V. Effects of three trials on grip and pinch strength measurements. J Hand Ther. 1990;3(4):195-8.

100. Trossman P, Li P. The effect of the duration of intertrial rest periods on isometric grip strength performance in young adults. Occup Ther J Res. 1989;9(6):362-78.

101. Coldham F, Lewis J, Lee H. The reliability of one vs. three grip trials in symptomatic and asymptomatic subjects. J Hand Ther. 2006;19(3):318-26.

102. Innes E. Handgrip strength testing: a review of the literature. Aust OccupTher J. 1999;46(3):120-4.

Received: $10 / 23 / 2013$ Recebido: 23/10/2013

Approved: 04/09/2014 Aprovado: 09/04/2014 